\title{
O FEMINISMO NA LITERATURA: A IMPORTÂNCIA DA VISIBILIDADE DA MULHER NO ENSINO DE LITERATURA NA EDUCAÇÃO BÁSICA ATRAVÉS DO TEXTO COMPANHEIRAS DE ENEIDA DE MORAES
}

\section{FEMINISM IN LITERATURE: THE IMPORTANCE OF WOMEN'S VISIBILITY IN TEACHING LITERATURE IN BASIC EDUCATION THROUGH THE TEXT COMPANHEIRAS BY ENEIDA DE MORAES}

\author{
Jessica Carolina de Souza Neves ${ }^{1}$ \\ Luana Beatriz Rodrigues de Souza ${ }^{2}$ \\ Pamella Cristina Requena ${ }^{3}$
}

Recebido em: 13 nov. 2019

Aceito em: 22 fev. 2020.

DOI 10.26512/aguaviva.v5i1.25849

RESUMO: O presente trabalho tem por objetivo apresentar uma prática docente de letramento literário por meio da crônica Companheiras, da escritora Eneida de Moraes, com a aplicação da sequência básica proposta por Rildo Cosson (2014) e das propostas da interação com o texto literário. Especificamente, o foco da pesquisa-bibliográfica de cunho qualitativo consiste em uma proposta de aplicação de um projeto de leitura para turmas de Ensino Médio. O intuito é mostrar a relevância da autoria e do protagonismo feminino nos estudos de literatura na educação básica, objetivando sistematizar prática de leitura motivacional que gere resultados satisfatórios quanto à interpretação da obra literária. A importancia do ensino da literatura se deve ao fato de que o primeiro contato no que tange ao desenvolvimento do indivíduo como leitor, na maioria das vezes, ocorre nas escolas. Ainda sob o ponto de vista teórico, busca-se entender as vozes das mulheres na literatura e trazer práticas de leitura segundo os estudos de Duarte (2003), Cosson (2014), Hollanda (1993), Cândido (1989) e em que medida o trabalho com o texto literário pode corroborar na aquisição de múltiplas linguagens pelos discentes. Destaca-se o poder humanizador que o texto literário possui sobre o indivíduo. Por fim, buscouse promover uma sequência didática humanizada, com vozes femininas, dialogando com os estudos culturais.

\footnotetext{
${ }^{1}$ Especialista em Ensino de Língua Portuguesa e Literatura pela Escola Superior da Amazônia (ESAMAZ). Email: jessicacarolinasouzaneves90@gmail.com

${ }^{2}$ Possui graduação em Letras - Língua Portuguesa pela Universidade da Amazônia (2018). Foi integrante do Programa de Pesquisa na Universidade da Amazônia, Grupo de Pesquisa Interfaces do Texto Amazônico - GITA durante o primeiro semestre de 2018. Especialista em Formação de Professores para o Ensino de Língua Portuguesa e Literatura na Escola Superior da Amazônia (ESAMAZ). Pesquisa acadêmica voltada para a identidade e representatividade da figura da mulher na Literatura, estudos culturais, relações de gênero, homossexualidade. E-mail: luana.rodriigues95@gmail.com

${ }^{3}$ Especialista em Ensino de Língua Portuguesa e Literatura pela Escola Superior da Amazônia (ESAMAZ). Possui graduação em Letras - Língua Portuguesa pela Universidade da Amazônia (2017). Tem experiência na área de Letras, com ênfase em Letras, Literatura e Redação. E-mail: pamellarequena@ hotmail.com
} 
Palavras-chave: Letramento literário. Amazônia. Crítica literária feminista.

ABSTRACT: The present work aims to present a teaching practice of literary literacy through the chronicle Companheiras, written by Eneida de Moraes, with the application of the basic sequence proposed by Rildo Cosson (2014) and the proposals of interaction with the literary text. Specifically, the focus of qualitative-bibliographic research is a proposal for the application of a reading project for high school classes, in order to show the relevance of female authorship and protagonism in literature studies in basic education, aiming to systematize motivational reading practice that generates satisfactory results regarding the interpretation of the literary work. Its importance is given since the first contact in the development of the individual as a reader most often occurs in schools. Also from the theoretical basis, the aim is to understand the voices of women in literature and to bring reading practices according to the studies of Duarte (2003), Cosson (2014), Hollanda (1993), Cândido (1989) and to what extent the work with the literary text can corroborate the acquisition of multiple languages by the students. We highlight the humanizing power which the literary text has over the individual. Finally, we sought to promote a humanized didactic sequence, with female voices, in dialogue with cultural studies.

Keywords: Literary literacy. Amazonia. Feminist literary criticism.

\title{
INTRODUÇÃO
}

Esta pesquisa tem como intuito mostrar a relevância da autoria e do protagonismo feminino nos estudos de literatura na educação básica, visto que o primeiro contato no que tange ao desenvolvimento do indivíduo como leitor, na maioria das vezes, ocorre nas escolas. Deste modo, ressalta-se a importância do ensino de literatura para a construção do senso crítico do aluno atrelado a outras ciências humanas. Para Lima e Lopes (2015)

\begin{abstract}
A função primordial da literatura é formar e transformar a vida do aluno com racionalidade e possiblidade de escolhas. O texto literário é matéria prima indispensável aos alunos desde pequenos. A escola precisa acordar e se posicionar frente a essa problemática e entender que é através da literatura que o indivíduo se transforma interiormente, no plano mental, pode ser sensibilizado, aumentar a sua criticidade frente às diversidades do mundo (LIMA \& LOPES, 2015, p. 4).
\end{abstract}

Dito isto, nota-se que a literatura tem um papel crucial na formação humanística de cada cidadão e para que sejam elaboradas aulas eficientes, pensou-se em utilizar as metodologias de Rildo Cosson. A fim de que se entenda melhor, Cosson se utiliza do termo letramento, porém aborda-se mais que alfabetizar estas pessoas no letramento literário 
Trata-se não da aquisição da habilidade de ler e escrever, como concebemos usualmente a alfabetização, mas sim da apropriação da escrita e das práticas sociais que estão a ela relacionadas. [...] o processo de letramento que se faz via textos literários compreende não apenas uma dimensão diferenciada do uso social da escrita, mas também, e sobretudo, uma forma de assegurar seu efetivo domínio (COSSON, 2014, p. 11-12).

Ademais, a literatura pode ser usada como ferramenta para abordar todo o tipo de assunto, neste ínterim, pensou-se em um estudo baseado nas sequências básicas de Cosson para discutir-se as relações de gênero na literatura. A terceira onda do feminismo fez-se muito forte quanto aos estudos literários, sendo assim

É inegável que o pensamento crítico feminista no Brasil, em fase de expansão e formação de um corpus teórico próprio, pelo menos na área das letras, já mostra quantitativa e qualitativamente sinais de seu potencial crítico e político. É inegável também [...] que a atual voga dos estudos feministas não é apenas mais uma moda acadêmica, mas é um entre os muitos resultados da longa trajetória das mulheres, com idas e vindas, estratégias e lutas, em busca não só de seus direitos civis, mas também de seu inalienável direito de interpretação (HOLLANDA, 1993, p. 34).

Consequentemente, o presente trabalho busca ressaltar a importância do ensino de literatura e utilizar-se deste modo de transmissão de conhecimento para dialogar com os estudos culturais, os quais discutem as tantas faces da sociedade no trabalho artístico através da escrita. As mulheres precisam se ver na arte, se identificar e não apenas reproduzir estes moldes patriarcais e machistas que há tanto vêm se consolidado na cultura geral. A prática da leitura crítica pode ocasionar a mudança de paradigmas e a construção de uma sociedade mais igualitária para todas as identidades de gênero.

Para o desenvolvimento desta pesquisa buscou-se responder a seguinte questão: Como utilizar o ensino de Literatura na Educação Básica de forma promover o empoderamento feminino?

No mais, este estudo justifica-se pelo fato de discutir acerca da lacuna existente no uso da Literatura Feminina no Ensino de Literatura na Educação Básica, trazendo com isso dados importantes para o ambiente escolar no que diz respeito aos textos literários de autoria feminina como objeto de estudo e ferramenta de letramento literário.

Desta forma, a presente pesquisa busca mostrar a relevância da mulher na literatura, quem são essas vozes que contam histórias e emocionam. Assim como acrescentar o trabalho dessas mulheres ao ensino do letramento literário, utilizando as etapas da sequência básica do autor Rildo Cosson, que na construção de seus pressupostos teóricos, trabalha com teorias 
linguísticas sobre o processamento sociocognitivo da leitura, discutindo questões importantes como decodificação, interpretação e construção de sentido de um texto.

Portanto, o objetivo geral é pesquisar sobre o feminismo na literatura, sua importância no ensino de Literatura na Educação Básica para o empoderamento feminino. E como objetivos específicos tem-se (i) especificar a importância do ensino de literatura na vida do aluno; (ii) discutir sobre o feminismo na literatura; (iii) apresentar metodologias de ensino de literatura aliados a discussão das relações de gênero e o empoderamento feminino.

A pesquisa está dividida em quatro partes, sendo que no primeiro momento apresentase a metodologia utilizada para a realização do trabalho e na segunda parte optou-se por mostrar o referencial teórico que daria o embasamento para discussão e desenvolvimento. O terceiro tópico ocupou-se de demonstrar a sequência básica proveniente de técnicas sugeridas baseadas no Letramento Literário e por fim, a discussão dos resultados acerca do tema abordado e a relevância na sala de aula.

\section{MÉTODOS E TÉCNICAS}

O presente trabalho constitui-se através de uma pesquisa bibliográfica e exploratória de cunho qualitativo. Lakatos e Marconi (2005, p. 185) afirmam que a pesquisa bibliográfica "não é mera repetição de que já foi dito ou escrito sobre certo assunto, mas propicia o exame de um tema sob novo enfoque ou abordagem, chegando a conclusões inovadoras". Enquanto, segundo Creswell (2010, p. 185) define qualitativa como "um meio para explorar e para entender o significado que os indivíduos ou os grupos atribuem a um problema social ou humano".

A pesquisa é também uma pesquisa ação, pois sugere-se ao final do trabalho uma sequência básica como formulação de uma estratégia de ensino que envolva o Letramento Literário. Sendo que uma das etapas levaria os alunos a refletirem a respeito do feminismo na Literatura, da representatividade da mulher na Arte literária e empoderamento feminino.

Dito isto, os métodos qualitativos usados neste trabalho foram leituras de artigos e livros que abordavam a respeito de feminismo e letramento. As técnicas usadas na pesquisa foram encontrar obras escritas por mulheres e levar tais textos como forma de representatividade e empoderamento feminino ao ensino básico de literatura.

\section{REFERENCIAL TEÓRICO}


O estudo tem por base os apontamentos teóricos de Duarte (2003), Cosson (2014), Hollanda (1993), dentre outros autores cujos escritos contribuirão para que se entenda melhor sobre a relevância da mulher na literatura, quem são essas vozes que contam histórias e emocionam, além de apresentar como utilizar o ensino de Literatura na Educação Básica de forma que promova o empoderamento feminino.

Este projeto busca mostrar por meio de análise de artigos e apontamentos de teóricos no assunto, que muito se tem discutido sobre a necessidade de um trabalho com a Literatura Feminina no âmbito da Escola Básica que possa favorecer o letramento literário do aluno-leitor e, em consequência disso, alargar suas possibilidades de vivências com o texto literário.

\subsection{Literatura e Direitos Humanos}

À guisa de início da discussão quanto ao ensino de Literatura na Educação Básica, vale ressaltar o poder humanizador que o texto literário possui sobre o indivíduo. Parte da construção humanística e do senso crítico deste cidadão em formação se dá através do ensino e aprendizagem da Literatura. A pesquisa retoma a fala de Antônio Candido, um dos autores mais importantes no que tange aos estudos literários juntamente aos Estudos Culturais ${ }^{4}$ no Brasil, onde se diz

Vista deste modo a literatura aparece claramente como manifestação universal de todos os homens em todos os tempos. Não há povo e não há homem que possam viver sem ela, isto é, sem a possibilidade de entrar em contato com alguma espécie de fabulação (CANDIDO, 1989, p. 4).

Dito isto, ressalta-se sobre o ato de ler como algo essencial para cada indivíduo em seu meio social. A sua visão de mundo está atrelada a forma como ele lê o que está a rodeá-lo, seja no campo profissional, nas relações interpessoais e até mesmo em momentos remotos do cotidiano.

\footnotetext{
${ }^{4}$ De uma forma geral, chamamos Estudos Culturais à disciplina que se ocupa do estudo dos diferentes aspectos da cultura, envolvendo, por exemplo, outras disciplinas como a história, a filosofia, a sociologia, a etnografia, a teoria da literatura, etc. Trata-se de uma disciplina académica, cujas origens é possível determinar, sendo habitual ligar essa origem ao próprio desenvolvimento do pós-modernismo e às suas celebrações contra a alta-cultura e as elites sociais, aos seus debates sobre multiculturalismo que têm tido particular expressão nos Estados Unidos, à sua ênfase nos estudos sobre pós-colonialismo, que ajudaram a criar uma nova disciplina dentro dos Estudos Culturais, e às suas manifestações sobre cultura popular urbana, por exemplo (CEIA, 2009).
} 
Todavia, há que se considerar, nessa circunstância, a atividade de leitura não somente para decodificar signos, mas antes de tudo como um despertar do senso crítico e a capacidade de desenvolver neste ser humano a autonomia de pesquisar, argumentar e formar ideias concretas. Sendo assim, faz com que seja possível a este leitor em formação criar prudência quanto ao que consome e difunde, assim como a acumulação de conhecimentos variados em diversos contextos.

Portanto, é por meio da leitura que este cidadão expande a sua bagagem cultural e seu repertório linguístico. Ademais, no meio social escolar, são realizadas leituras intrínsecas aos planos curriculares e na influência mútua entre pessoas, a troca de informações com diferentes perspectivas, contribui para a concretização de uma prática de leitura que necessita ser aprimorada diante das cobranças quanto ao progresso escolar no decorrer de toda a vida.

\subsection{A crítica literária feminista}

Dito isto, ao se trabalhar a importância e o direito que as pessoas possuem de entrar em contato com o texto literário e a boa compreensão do mesmo, evidencia-se a crítica quanto ao cânone literário que em sua maioria traz somente autores masculinos. Desta forma, a presente pesquisa busca abordar as influências feministas nos estudos literários e sugere metodologias para a transmissão de conhecimento acerca da escrita feminina, não apenas protagonizada por mulheres, mas de autoria feminina.

Sendo assim, busca-se romper com paradigmas tão bem estruturados dentre vários séculos de obras literárias escritas por homens e somente pensadas através da perspectiva masculina, portanto, têm-se as várias representações femininas, as quais corroboraram para os tantos estereótipos sobre a imagem da mulher sustentados pelo sistema patriarcal.

Neste quesito, quanto aos estigmas consolidados por obras do cânone literário, diz Lúcia Osana Zolin (2009, p. 226): “o da mulher sedutora, perigosa e imoral, o da mulher como megera, o da mulher indefesa e incapaz e, entre outros, o da mulher como anjo capaz de se sacrificar pelos que a cercam”, sempre a imagem da mulher sendo pensada em função de um homem.

Para se contrapor a isto, surgiu em meados das décadas de 1970 e 1980 no Brasil, a crítica literária feminista. Este modo de pensar o texto que fala da mulher, o texto escrito por uma mulher, debruça-se sobre a mudança de perspectiva quanto ao papel social da antiga e da nova mulher. Posto isto, notar-se-á grande influência dos movimentos feministas nos estudos 
culturais e por conseguinte, na crítica literária. A fim de elucidar esta ligação do movimento feminista ao papel político da Literatura, citamos Constância Lima Duarte:

Penso que o 'feminismo' poderia ser compreendido em um sentido amplo, como todo gesto ou ação que resulte em protesto contra a opressão e a discriminação da mulher, ou que exija a ampliação de seus direitos civis e políticos, seja por iniciativa individual ou de grupo. Somente então será possível valorizar os momentos iniciais desta luta - contra os preconceitos mais primários e arraigados - e considerar aquelas mulheres, que se expuseram à incompreensão e à crítica, nossas primeiras e legítimas feministas (DUARTE, 2003, p. 155).

\subsubsection{As transformações sociais e as relações de gênero}

Primordialmente, a fim de explicitar as transformações no âmbito sociocultural acerca da história das mulheres e da importância dessa perspectiva para os Estudos Culturais, faz-se necessária uma breve contextualização sobre como essa nova vertente passou a ser escrita.

No final do século XIX e a partir do século XX vê-se uma amálgama de mudanças nesse aspecto, muitos questionamentos oriundos de movimentos sociais passam a influenciar os discursos acadêmicos e as questões de gênero adentram o meio intelectual.

Para pensar as mulheres de forma mais completa, as descobertas sobre a sexualidade feminina revolucionam a forma de pensar as identidades de gênero, mostrando que existe mais que uma mulher angelical ou prostituta. $\mathrm{O}$ sujeito reconhecendo-se como feminino possui muitos outros desdobramentos além do que sempre foi ensinado e propagado de forma mais aberta pela cultura em geral. $\mathrm{O}$ acesso à informação sobre estas outras formas passa a mudar o pensamento coletivo de forma gradativa e os pormenores começam a ser evidenciados.

A sexualidade humana não tem apenas a procriação como finalidade e isso passa a ser questionado com maior frequência desde que os ofícios intelectuais passam a ser melhor distribuídos entre pessoas de diferentes gêneros. Para que se problematize a construção e influência da Literatura como ideologia, é importante fazer uma abordagem histórica sobre as mulheres e os movimentos sociais.

A relevância da história das mulheres e seu papel social através dos séculos faz com que haja uma melhor compreensão da sociedade como um todo, pois muito do que foi ensinado e expandido sobre a conduta feminina era realizado por homens. Nota-se a diferença das 
narrativas desde que os excluídos passaram a ser sujeitos sociais, a mudança de perspectiva desde que grupos silenciados começaram a ter voz.

Por conseguinte, se aquele grupo possui uma memória, ele possui um discurso, portanto, nas relações de poder, passa a existir. No entanto, as ciências, a política, as artes e a cultura de forma geral foram desenvolvidas de forma restrita a homens na maior parte da história ocidental, cabendo a eles o papel da vida intelectual, social e laboral. Em contrapartida, às mulheres restava a esfera da casa e da família e desta forma, suas representações serão demarcadas assim, apenas como esposas, mães, filhas, amantes, etc.

No que se refere a esta condição e o porquê apresentado por meio de análises historiográficas,

\footnotetext{
Em primeiro lugar, porque as mulheres são menos vistas no espaço público, o único que, por muito tempo, merecia interesse e relato. Elas atuam em família, confinadas em casa, ou no que serve de casa. São invisíveis. Em muitas sociedades, a invisibilidade e o silêncio das mulheres fazem parte da ordem das coisas. É a garantia de uma cidade tranquila. Sua aparição em grupo causa medo (PERROT, 2007, p. 16, 17).
}

Há de se perceber por intermédio de relatos das sociedades anteriores que a estas mulheres era vedada a atuação social fora do ambiente domiciliar. Portanto, quando elas são retratadas, estes assuntos domésticos são recorrentes por fazerem parte do meio no qual elas vivem.

Pelo fato dos homens deterem o poder de fala, "As mulheres são imaginadas, representadas, em vez de serem descritas ou contadas. Eis aí outra razão para o silêncio e a obscuridade: a dissimetria sexual das fontes, variável e desigual segundo as épocas” (PERROT, 2007, p. 17).

A modernidade, que tem seu início datado a partir do século $\mathrm{XV}$, trazendo o renascimento cultural como marca transitória, traz também a condição social feminina sofrendo uma involução. Neste período, o acesso a diversas profissões e até mesmo a educação passam a ser restritos devido ao advento das navegações nas quais os homens exerciam o seu protagonismo e optaram por confinar as damas ao ambiente domiciliar.

Nesse meio tempo, no entanto, em relação as alternativas da vida social feminina ocorrem tentativas somente com o surgimento das ideias iluministas e a Revolução Francesa. 
Portanto, é no século XVIII que o direito das mulheres passa a ser reivindicado e neste ínterim, as primeiras escritoras consideradas feministas surgem. A exemplo de Olympe de Gouges, Mary Wortley Montagu e Mary Wollstonecraft, a última sendo a mais conhecida e tendo como trabalho notável, Uma reivindicação pelos direitos da mulher (1792).

Durante a Revolução Industrial, no século XIX, de acordo com Duarte (2003, p. 155), as mulheres passaram a ficar mais presentes no mundo trabalho, embora houvesse grande discrepância entre os salários. Nesta conjuntura, as ideologias do movimento socialista se consolidaram e o movimento feminista tornou-se um grande aliado.

No Brasil, as indagações de caráter feminista começam através dos escritos de Nísia Floresta, que publica Direito das mulheres e injustiça dos homens (1832). É na última década deste século que aparecem maiores incidências dos movimentos sufragistas ao redor do mundo, principalmente após a conquista deste direito na Nova Zelândia em 1893, lugar em que Kate Sheppard liderou as manifestações, o assunto passou a ser discutido em todos os países no mundo ocidental.

Baseando-se em informações de Narvaz \& Koller (2006, p. 649), foi em 1897 que o movimento social pelo sufrágio feminino começou na Inglaterra, de forma pacífica e liderado por Millicent Fawcett. Todavia, parte das sufragistas passaram a agir de forma mais enérgica no início do século XX, quando Emmeline Pankhurst, da União Social e Política das Mulheres (Women's Social and Political Union - WSPU) fazia greves de fome e cometia pequenas infrações resultando em embates com a polícia.

Em conformidade com Pinto (2010, p. 15) "Em 1913, na famosa corrida de cavalo em Derby, a feminista Emily Davison atirou-se à frente do cavalo do Rei, morrendo. O direito ao voto foi conquistado no Reino Unido em 1918”. Apenas cinco anos após o ocorrido e pela ajuda exercida por estas ativistas na Primeira Guerra Mundial.

Ainda consoante Pinto (2010, p. 16), no Brasil, o movimento começou em 1910 e foi liderado por Bertha Lutz, que iniciou a luta pelo voto assim que voltou de uma temporada de estudos na Europa: "Este direito foi conquistado em 1932, quando foi promulgado o Novo Código Eleitoral brasileiro". Após a conquista do direito ao voto, tanto no Brasil como em outros países de cultura ocidental, não houve mais tantas contestações.

Apesar disso, em 1949, a filósofa francesa existencialista Simone de Beauvoir publica um livro que mudará a perspectiva acerca das mulheres, $O$ Segundo Sexo, obra na qual a autora demonstra a hierarquia entre os sexos como uma construção social e não uma característica 
biológica e inata. Acredita-se que foi uma das grandes referências para a segunda onda do feminismo, que tem seu início na década de 60 do século XX.

Grande parte da militância feminista na segunda metade do século XX caracterizava-se por um perfil de mulheres intelectuais, grande parte proveniente das áreas de Crítica Literária, Humanidades e Psicanálise, sendo assim, aliaram militância e teoria. Consequentemente,

tanto os movimentos feministas quanto a sua teoria transbordam seus limites, provocando um interessante embate e reordenamento de diversas naturezas na história dos movimentos sociais e nas próprias teorias das Ciências humanas em geral (PINTO, 2010, p. 15).

É neste período compreendido entre as décadas de 60 e 80 do século XX que muitas pautas passarão a ser debatidas, como a sexualidade, as desigualdades, a família, o mercado de trabalho, a violência doméstica, o estupro conjugal, divorcio, leis de custodia, etc. Faz-se importante destacar estes debates que começaram a falar na sexualidade da mulher, pois consoante Perrot (2007, p. 63) "De Aristóteles a Freud, o sexo feminino é visto como uma carência, um defeito, uma fraqueza da natureza".

A partir da década de 80, haverá a chamada terceira fase ou onda do feminismo, na qual nota-se a introdução da crítica pós-modernista sobre "o paradigma da incerteza no campo do conhecimento" (NARVAZ \& KOLLER, 2006, p. 649).

Na França, as feministas terão influência do pós-estruturalismo, mormente pelas teorias de Michel Foucault e Jacques Derrida quando "passam a enfatizar a questão da diferença, da subjetividade e da singularidade das experiências, concebendo que as subjetividades são construídas pelos discursos, em um campo que é sempre dialógico e intersubjetivo" (PEREIRA, 2004 apud NARVAZ \& KOLLER, 2006, p. 649).

E de forma mais sucinta sobre as contribuições desta terceira onda feminista,

[...] concentra-se na análise das diferenças, da alteridade, da diversidade e da produção discursiva da subjetividade. Com isso, desloca-se o campo do estudo sobre as mulheres e sobre os sexos para o estudo das relações de gênero. [...] O desafio nesta fase do feminismo é pensar, simultaneamente, a igualdade e a diferença na constituição das subjetividades masculina e feminina (NARVAZ \& KOLLER, 2006, p. 649).

Portanto, neste âmbito, os Estudos de Gênero ganham espaço na academia tanto quanto em vários países do mundo ocidental, a exemplo do Brasil. As três gerações do feminismo possuem características que sempre coexistiram, porém houve mais enfoque de alguns assuntos 
em determinadas fases e assim, as divisões em ondas ou fases foram posteriormente estabelecidas.

\subsection{Letramento Literário}

Para além dos preceitos teóricos quanto aos estudos literários e os assuntos condizentes com o papel da mulher na sociedade, esta pesquisa busca como sugestão o trabalho de Letramento Literário (COSSON, 2014) com a sequência básica quanto a um texto de autoria feminina. Visto que, (VIEIRA, 2015, p. 4) "Valendo-se de perspectivas transculturais, enfatiza a natureza social do letramento, em oposição ao que denomina de perspectiva "autônoma", orientada para as habilidades". Portanto, a abordagem dessa história de mulheres sob a perspectiva de outras mulheres fará com que o aluno relacione a habilidade da leitura e da escrita para o desenvolvimento de práticas sociais e valores.

Com este fim, serão trabalhados os quatro passos da sequência básica proposta por Rildo Cosson: a motivação, introdução, leitura e interpretação. Falar-se-á nos movimentos feministas para deixar os estudantes familiarizados com a importância nessa mudança de ponto de vista, apresentando nomes notáveis de mulheres importantes na história e na Literatura até chegar ao texto escolhido. Deste modo, a obra escolhida será o texto Companheiras de Eneida de Moraes, representando a literatura de expressão amazônica e a ambientação da influência feminista na história do país.

\section{METODOLOGIAS DE ENSINO DE LITERATURA ALIADAS A DISCUSSÃO DAS RELAÇÕES DE GÊNERO E EMPODERAMENTO FEMININO}

A proposta de sequência básica tem por objetivo apresentar uma prática docente de letramento literário por meio da crônica Companheiras, da escritora Eneida de Moraes, com a aplicação da sequência básica proposta por Rildo Cosson (2014) desejando propor uma interação com o texto literário. Especificamente, para os alunos de Ensino Médio, objetivando sistematizar prática de leitura motivacional que gere resultados satisfatórios quanto à interpretação da obra literária e apresentação da figura da mulher na literatura. 
Partimos da compreensão de que o texto literário no ambiente escolar busca "reformar, fortalecer e ampliar a educação literária que se oferece no ensino básico” (COSSON, 2014, p. 12). Logo, seguimos a sequência básica composta por quatro passos: motivação (preparar os leitores), introdução (apresentar leitor e obra), leitura (contato com o texto) e interpretação (inferências) (COSSON, 2014). Quando cumpridas cada uma das etapas, será possível acrescentar a produção textual de vários gêneros, bem como compartilhar tais experiências com a organização de exposições dos trabalhos apresentados.

Ao estabelecer os passos das sequências, as práticas possibilitam a fruição da leitura literária em sala de aula, fundamental ao processo educativo. A sequência básica aqui descrita como uma pesquisa-ação é, portanto, uma das inúmeras possibilidades de leitura motivadora do texto literário nas escolas brasileiras.

\subsection{A crônica Companheiras de Eneida de Moraes}

\section{Companheiras $^{5}$}

Durante o inverno a sala era tão úmida, tão fria que enregelava mãos e obrigava os pés a manter um constante sapateado; no verão a sala era quente, tão quente que parecia querer matar-nos sufocadas a qualquer momento.

Os dias - no inverno como no verão - se arrastavam pesados, longos, sem monotonia, pois nossa constante preocupação era inventar formas para que eles não fossem parecidos. Enchíamos com coragem e alegria todas as horas: ginástica, estudo, conversas, cânticos, passeio. Tão pequeno o espaço que possuíamos para caminhar, e o ruído dos tamancos cortava-o, ferindo o lajedo; as saudades impressas nos olhos; as constantes evocações. Quando se falava em quitutes variados, quando alguém dizia como se preparava esse ou aquele prato, podia-se olhar os olhos: estavam todos famintos. Quando se contavam passeios e se falava de mar, praia, montanhas ou planícies, podia-se ver nos olhos famintos uma ânsia de voltar à vida da cidade, da terra, do mundo.

Éramos vinte e cinco mulheres presas políticas numa sala da Casa de Detenção, Pavilhão dos Primários, 1935, 1936, 1937, 1938. Quem já esqueceu o sombrio fascismo do Estado Novo com seus crimes, perseguições, assassinatos, desaparecimentos, torturas?

De um lado e do outro da sala, enfileiradas, agarradas umas às outras, vinte e cinco camas. Quase presas ao teto alto, quatro janelas fechadas por umas tristes e negras grades. Encostada à parede, uma grande mesa com dois bancos. Ao fundo da sala, os aparelhos sanitários. Por maior que fosse a nossa luta para mantê-los limpos e desinfetados, nunca conseguimos fugir do cheiro que exalavam.

\footnotetext{
${ }^{5}$ MORAES, Eneida. Companheiras. In: MORAES, Eneida. Aruanda. Belém, PA: Secult, 1989. p. 130-138.
} 
Vinte e cinco mulheres, vinte e cinco camas, vinte e cinco milhões de problemas. Havia louras, negras- mulatas, morenas; de cabelos escuros e claros; de roupas caras e trajes modestos. Datilógrafas, médicas, domésticas, advogadas, mulheres intelectuais e operárias. Algumas ficavam sempre, outras passavam dias ou meses, partiam, algumas vezes voltavam, outras nunca mais vinham.

Havia as tristes, silenciosas, metidas dentro de si próprias; as vibráteis, sempre prontas ao riso, aproveitando todos os momentos para não se deixarem abater. Os filhos de Rosa eram nossos filhos. Sabíamos as graças e as manhas com que embalavam aquela mulher forte, arrogante, atrevida sempre mas tão doce, tão enlevada pelos “meninos”. Quando Rosa falava nos "meninos" ficávamos todas em silêncio. Onde andariam eles? A polícia arrancara-os daquela mãe, negava-se a informar onde se encontravam, não admitia que Rosa soubesse notícias da família: o marido foragido, a irmã distante. E os “meninos"? No silencio das noites, Rosa fazia com que assistíssemos nascimentos, aos primeiros passos, à primeira gracinha, ao primeiro sorriso, e depois o crescer rápido, a escola, os livros, idade avançando. Onde andariam eles?

Problemas de uma, problemas de todas. O noivo de Beatriz era o nosso noivo. Queríamos saber suas notícias, coisa que nem a própria noiva sabia. Problemas comuns, destinos comuns. Os filhos de Antônia estavam em Natal, mas andaria o marido de Nininha, preso no Rio Grande do Norte?

- Aquele eu conheço muito. É um cabra da peste. Ninguém dobra ele, não.

Nininha alourada, de voz cantante, opunha às cenas de doçura suas palavras de energia. Contava a vida do marido como a de um herói.

Pobres mulheres jogadas numa prisão infecta, sem o menor conforto. Maria pensava no seu chuveiro elétrico, Valentina ensinava literatura inglesa (como estudava e lia Valentina) e queríamos à viva forca que Nise desse lições de Psicologia.

Um dia - jamais esquecerei esse dia - fazia muito calor e havia sol. Pareciam maiores as paredes da sala onde escrevêramos desabafos. A vida lá fora deveria estar bela; era verão e com certeza ruas e avenidas ensolaradas viam passar mulheres de vestidos claros e leves. Na sala, aquela tarde, havia tanto calor que descansávamos nas camas, abanando-nos com pedaços de papel. Como não tínhamos espaço para andar todas ao mesmo tempo, quando umas o faziam, outras eram obrigadas a ficar sentadas ou deitadas nas camas. Jogávamos paciência, algumas, e o calor era tanto que nem tentávamos falar. Qualquer gesto, qualquer palavra ou movimento iria aumentar o suor que escorria de nossos corpos cansados. Não podíamos perder a menor de nossas energias: devíamos sobreviver.

Foi nessa tarde que tenho gravada na memoria que ela entrou na Sala das Mulheres. Nunca esquecerei seu ar de espanto nem aqueles sapatos que haviam sido brancos. Estavam manchados de terra ou de sangue? Nunca esquecerei o vestido sujo, as mãos trêmulas, os cabelos brancos revoltos.

Ouvimos os passos do guarda subindo a escada; as chaves na porta de grades; depois ela entrou. Estatura mediana, vestido estampado, olhos curiosos. Entrou em silêncio. Em silêncio o guarda a deixou ali.

Olhou em torno. Procurou examinar uma a uma as mulheres, envolvendo-as todas num olhar imenso. Sentou-se na ponta de uma cama próxima, curvou-se meteu os dedos por entre os cabelos.

- Quem será?

- Que mulheres serão estas? - estaria se perguntando.

Aproximamo-nos. Tínhamos sempre o cuidado de fazer o reconhecimento e o nosso próprio interrogatório: de onde vem, que fez, por que foi presa, seu nome, etc. Muitos etc. 
Perguntamos quem era ela. Nenhuma resposta. Ninguém a conhecia; não nos conhecia. Insistimos. Levantou os olhos, encarou-nos de frente, parecia um animal pronto a se defender. Nossas perguntas foram feitas em várias línguas. E ela continuava firme, sem a menor perturbação fisionômica.

- Não sabemos quem é você. Mas nós somos antifascistas, nós somos presas políticas. Cada uma de nós tem sua estória; esta veio presa do Norte, aquela está aqui como refém porque o marido sumiu. Somos todas brasileiras.

Uma de nós adiantou-se e lhe disse:

- Eu sou comunista.

Foi a esse grito que aquela mulher despertou. Agarrou-se à companheira, beijou-lhe o rosto e pôs-se a exclamar com grandes lágrimas descendo pelo rosto alquebrado:

- Camarada, minha camarada!

O olhar com que agora envolvia as vinte e cinco mulheres era diferente; queria entender as palavras nas paredes, perguntava, sorria, abraçava todas, chorava e ria. E contou. Contou com voz firme o quanto sofrera. A Polícia Especial a maltratara monstruosamente. Mostrou-nos os seios onde trazia impressas marcas de dedos. Colocavam-na no alto da escada, amarrada e nua para forçá-la a declarar ou delatar, enquanto dois homens enormes lhe puxavam os seios.

Falou-nos do sofrimento, da fome e da sede que lhe haviam imposto. Falou-nos de seu companheiro e das barbaridades que ambos padeceram. Falou sempre com voz clara, precisa, serena, em tudo que passara nas prisões desta cidade. Seu corpo guardava ainda as vergastadas do chicote policial. Jogavam-na de prisão em prisão. Ora era metida em celas de prostitutas, ora no meio de ladras ou ébrias. Durante mais de dois meses sofreu humilhações físicas e morais.

- Muito ruins, muito ruins, comentava.

Uma de nós falou:

- Ela precisa comer, tomar banho, mudar o vestido.

Houve um corre-corre geral. Todas queriam dar-lhe roupas, todas queriam dar-lhe um pedaço de pão, de doce, uma fruta. Comia sorrindo. Sua fome tinha dois meses, seu sofrimento mais algum tempo.

Minutos depois voltou o guarda. Explicou que fora engano. A prisão para ela seria outra. E sorrindo:

- Muito pior.

Quando partiu, deixava vinte e cinco amigas. Não lhe dissemos adeus, não tivemos um momento de fraqueza. Mas quando as grades se fecharam atrás dela, cinquenta olhos choraram.

A tarde tão quente de verão foi mais longa e dolorosa naquele dia. Ninguém falava. Voltamos ao jogo de paciência, ao silêncio, à angustia de saber que a vida lá fora devia andar linda.

Três meses depois ela voltou. Veio viver conosco. Todas as noites, à meia-noite, levantava-se e andava, andava de um lado para outro, sem uma palavra.

- De meia-noite às duas da manhã ela devia apanhar; ficou-lhe uma psicose.

Essa mulher se chamava Elisa Soborovsk, a Sabo Berger, mulher de Henry Berger. O governo Getúlio Vargas entregou-a mais tarde à Gestapo. Hitler matou-a. 
Sabo, para mim, foi uma revelação: jamais conheci mulher tão culta, tão humana, tão valente. Uma mulher tão bela. Nunca a esquecerei.

Na noite em que ela partiu com Olga Benário para o navio que as levaria a Hitler, era inverno e tiritávamos de frio. Sofríamos ainda mais, porque tínhamos aprendido a amá-la.

Recordando-a agora, cumpro um dever. Jamais esquecerei também as vinte e cinco mulheres da sala ora fria, ora quente, do Pavilhão dos Primários.

Grandes mulheres; boas companheiras.

\subsection{Análise literária da Crônica}

A crônica Companheiras relata uma história memorialista da política brasileira e das injustiças sociais ocorridas no período da Ditadura do Estado Novo. O texto é narrado em primeira pessoa, onde a narradora vivencia os fatos em uma Casa de Detenção perpetuando uma experiência de horror e repressão no período do Estado Novo. É percebida na narrativa a presença de uma narradora-personagem, apresentando-se como um grande diferencial, a mesma não é identificada como protagonista, apenas compartilha acontecimentos comportando-se como as demais personagens envolvidos no enredo. Como também, em todo decorrer do texto é notável a utilização dos vocábulos no plural: "Éramos vinte e cinco mulheres presas políticas.", "Pobres mulheres jogadas na prisão, sem menor conforto." e "Ouvimos os passos do guarda subindo a escada", enfatizando que aquele sofrimento pertencia de igual a todas, e que elas, mulheres companheiras, eram protagonistas da própria história.

O texto é iniciado com a descrição da precariedade do ambiente, e dos objetos que eram negados às presas políticas para suprir suas necessidades básicas. O texto deixa claro que o recinto era inadequado àquelas mulheres, revelando um espaço pequeno para acomodar o número de pessoas ali alojadas, os aspectos caracterizados do local já especificam uma tortura física e psicológica a qualquer ser humano, aparentando um lugar de pavor.

A linguagem simples e clara expõe os fatos, evidenciando a forma de desumanização a que as pessoas eram expostas nos âmbitos carcerários, não lhes ofereciam o mínimo de dignidade, eram tratadas com as piores condições possíveis, para enfatizar o poder centralizador e opressor do regime ditatorial, focando o resultado daqueles que transgrediam as ideologias dos seguidores da ditadura getulista.

O tema político é bem enfatizado dentro do texto, deixando nítida a opinião crítica da autora a respeito do autoritarismo, antidemocracia e repressão do governo getulista no contexto que a 
narradora vivenciava.

Éramos vinte e cinco mulheres presas políticas numa sala de Casa Detenção, Pavilhão dos Primários, 1935, 1936, 1937, 1938. Quem já esqueceu o sombrio facismo do Estado Novo com seus crimes, perseguições, assassinatos, desaparecimentos, torturas? (MORAES, 1989, p.131).

Essas recordações pessoais da escritora são apresentadas em outros parágrafos do texto. "Recordando agora cumpro um dever. Jamais esquecerei também as vinte e cinco mulheres da sala ora fria, ora quente, do Pavilhão dos Primários" (MORAES, 1989, p. 138). Portanto, neste fragmento fica evidente na narrativa uma situação de recordações parcialmente mais íntimas da narradora, construída a partir das experiências adquiridas, do seu conhecimento de mundo, como também diz respeito à memória daquele grupo de mulheres vítimas da ditadura.

De meia noite às duas da manhã ela devia apanhar; ficou-lhe uma psicose. Essa mulher se chamava Elisa Sobopovsk, a Sabo Berger, mulher de Henri Berger. O governo Getúlio Vargas entregou- a mais tarde à Gestapo. Hitler matou-a. Sabo para mim foi uma revelação; jamais conheci mulher tão culta, tão humana, tão valente. Uma mulher tão bela. Nunca a esquecerei. Na noite que ela partiu com Olga Benário para o navio que as levaria a Hitler (MORAES, 1989, p.137).

A partir desse fragmento pode-se comprovar o que fora abordado anteriormente, a respeito do processo de entrelaçamento que se refere à memória coletiva e individual. Num primeiro momento do trecho é notável o entendimento da memória coletiva, quando refere-se às personagens de Sabo Berger e Olga Benário, personalidades importantes na luta contra os horrores do fascismo. Como também, quando fora aludido a Getúlio Vargas e Hitler, acionase lembranças de um dado momento histórico dos horrores da ditadura estadonovista no Brasil e os requintes de crueldades do holocausto provocados pelo nazismo na Alemanha.

Pode-se dizer que tanto a memória individual quanto a memória coletiva na crônica Companheiras são expressas de forma intensa e clara do início ao fim da narrativa, chegando a ser confundida a biografia da autora com a voz da narradora, demonstrando assim uma das características do gênero literário crônica. $\mathrm{O}$ texto retrata momentos de bravura e determinação de mulheres que lutavam por uma sociedade mais justa e democrática, num momento em que elas ainda não tinham conquistado um espaço de igualdade de voz e de vez numa nação que ainda sobrevive à cultura patriarcal. A autora a partir de uma visão crítica recorre à literatura 
cristalizando um fato histórico, promovendo uma reflexão a partir do imaginário do leitor.

\subsection{Descrição das etapas}

Durante a aplicação da leitura da crônica - realizada extra classe - haverá uma sistematização, reservando-se uma aula semanal para a sua compreensão. A cada semana, novos objetivos e atividades serão realizadas em sala de aula. A validade da estratégia aqui tabulada, no entanto, é reconhecida perante a leitura, inferências e produções dos alunos que integrarão a prática.

Desta forma, segue-se o passo a passo da aplicação deste projeto que visa, sobretudo, a promoção do Letramento Literário e valorização da imagem da mulher na Literatura.

\subsubsection{Motivação}

Para Cosson (2014), as atividades de motivação podem garantir ou não o sucesso do encontro entre leitores e texto literário. É neste momento que eles são preparados para receber a obra, não silenciando, no entanto, o texto, tampouco o aluno.

Vale ressaltar que as discussões propostas no momento da motivação pretendem considerar as intervenções e interpretações de todo o alunado, pois são relevantes para a compreensão da obra literária, bem como seus efeitos de sentido, seja para reiterá-los ou confrontá-los durante as etapas posteriores.

\subsubsection{Introdução}

Haverá a apresentação do conto para a turma e, o professor pesquisador conduzirá uma breve análise sobre as possibilidades que levaram a escritora a produzir o texto. Na sequência, trabalhará o contexto histórico do mesmo.

Detalhes da vida da autora também serão explorados. Eneida de Moraes, foi uma jornalista, escritora, militante política e pesquisadora brasileira. Eneida é sempre descrita em relatos de amigos e parentes como uma mulher forte, viva, corajosa, audaciosa e inteligente; sempre buscando o reconhecimento e enaltecimento da luta da mulher amazônica.

Norteados pelas asserções de Cosson (2014) sobre as atividades de introdução, os alunos serão levados a conhecer mais sobre os autores e entender o porquê de tal obra ter sido escolhida: trata-se de uma autora local e a temática da obra se faz relevante. Ambientada durante 
a ditadura estadonovista, conta a história de um grupo de mulheres que sofreram diversos abusos em uma prisão. E mesmo com dificuldades, buscaram sempre manter-se unidas como verdadeiras irmãs. Demonstra a sororidade ${ }^{6}$ da mulher, como se a dor de uma fosse de todas as outras.

\subsubsection{Leitura}

\section{Leitura coletiva e individual}

Cosson (2014, p. 62) comenta que o professor, a partir desta atividade, deve acompanhar a leitura, sem confundir, porém, com policiamento; segundo o autor, convidando os alunos a apresentar o resultado das leituras durante os “intervalos", período que eles leem fora da sala de aula. O aluno também precisará ler a obra de maneira individual, para conhecer melhor o texto trabalhado, para fazer reflexões sobre o tema, analisar alguns personagens da história.

\subsubsection{Interpretação}

Os intervalos de leitura constituíram a quarta e última etapa da sequência, a interpretação. Nesses momentos serão propostas atividades que façam sentido dentro do contexto social do alunado, atribuindo ao leitor a tarefa de produtor de textos.

As atividades de produção que se realizarão na sequência serão importantes à medida que descortinarem a compreensão do texto. As produções, portanto, devem contemplar o diálogo entre o leitor e a obra, conferindo valor à leitura realizada. Para que haja a exploração da crônica e que tenha sentido para futuras produções textuais do aluno, o professor deverá fazer perguntas norteadoras para os alunos. Vejamos os exemplos abaixo:

a) Quais são suas impressões sobre o ambiente descrito pela narradora?

b) O título da crônica sugere alguns sentidos. Quais?

\footnotetext{
${ }^{6}$ A palavra que vem do latim soror (irmãs) significa irmandade, empatia e união entre mulheres. É entender a dor e os motivos da outra antes de apontar o dedo. É acreditar que juntas somos melhores, mais fortes, menos fragilizadas, mais capazes. Sororidade é uma das bases do feminismo e pode ser praticada de diversas formas, desde que a premissa seja sempre o apoio mútuo.
} 
c) Que fato do cotidiano a crônica que você leu explora?

d) Nesse texto, o narrador é personagem? Justifique sua resposta.

Sob a perspectiva de Cosson (2014, p. 27), segundo a qual “a leitura é um ato solitário, mas a interpretação é um ato solidário", tal atividade permitirá o compartilhamento de interpretações, perspectivas e dúvidas dos alunos, assim como os trechos em que tiveram dificuldades. Diferentes opiniões sobre o enredo e o final da crônica também serão discutidas. Dessa forma, a relação entre leitura, contexto e interpretação (individual e coletiva) será efetivada com o enriquecimento da leitura e, sobretudo, da compreensão do texto. Sobre o enredo e final do texto, os alunos farão análises sobre a crônica, munidos do que eles possuem de conhecimento a respeito do contexto histórico em que se passa o texto.

\section{RESULTADOS E DISCUSSÃO}

Para começar a discutir sobre Literatura na Educação Básica, é válido pensar nesta disciplina como a protagonista do processo de formação deste indivíduo leitor, uma vez que esta linguagem permite o contato com aspectos históricos, políticos e sociais representados no texto literário. A leitura é uma forma de contato por meio da linguagem verbal, sendo vista como uma das possíveis formas de interação dos seres sociais com outros membros da sociedade.

Ou seja, para os mais diversos modos de contato social, a boa leitura proporciona a decodificação das atividades simbólicas. Logo, o ato de ler faz com que seja possível a produção de sentidos para assim formar o leitor. Neste caso faz-se necessário considerar "a leitura não como o resultado satisfatório do processo de letramento e decodificação de matéria escrita, mas como atividade propiciadora de experiência única com o texto literário" (ZILBERMAN, 2008, p. 16).

Dito isto, em uma de suas palestras sobre o direito à literatura, Antônio Candido discute sobre o papel das inquietações quanto à sociedade trazida no texto ficcional. Contudo, sobre o poder humanizador da obra literária, diz Candido (2008, p. 6) “O processo de humanizar requer o exercício da reflexão, a aquisição do saber, a capacidade de penetrar nos problemas da vida, o senso de beleza, a percepção da complexidade do mundo". 
Sendo assim, esta humanização pode causar as reflexões que permitem a produção do confronto entre a leitura e a experiência de vida do leitor, levando-o a pensar de forma crítica sobre a realidade na qual está inserido. É também por meio deste processo que o aluno tem a oportunidade de conhecer diversas culturas fazendo pensar no seu papel humanístico.

Desta forma, discutir assuntos que fazem parte da vivência deste cidadão em formação a partir dos textos de cunho literário podem fazê-lo identificar o seu lugar no mundo, assim

\begin{abstract}
A leitura do texto literário constitui uma atividade sintetizadora, permitindo ao indivíduo penetrar o âmbito da alteridade sem perder de vista sua subjetividade e história. $\mathrm{O}$ leitor não esquece suas próprias dimensões, mas expande as fronteiras do conhecido, que absorve através da imaginação e decifra por meio do intelecto. Por isso, trata-se também de uma atividade bastante completa, raramente substituída por outra, mesmo as de ordem existencial. Essas têm seu sentido aumentado, quando contrapostas às vivências transmitidas pelo texto, de modo que o leitor tende a se enriquecer graças ao seu consumo (ZILBERMAN, 2008, p. 17).
\end{abstract}

Neste contexto, cabe ao professor de língua portuguesa e literatura mostrar e incutir esta valorização da disciplina para o ensino de modo geral, fazendo os alunos entenderem a importância da boa leitura. Serão criados, assim, mecanismos que capacitem esse leitor a desfrutar, decodificar e significar o que lê. Este trabalho é imprescindível pois "põe em foco o leitor e seus conhecimentos em interação com o autor e o texto para construção de sentido [...]" (KOCH e ELIAS, 2008, p. 13).

Faz parte da experiência do professor em sala de aula ponderar sobre os conhecimentos deste aluno-leitor, visto que cada um irá se diferenciar e levar consigo uma bagagem cultural única, o que ocasionará em múltiplas formas de interpretação de um mesmo texto. De todo modo, cada leitura deve possuir um mínimo de coerência, levando em consideração que "o sentido não está apenas no leitor, nem no texto, mas na interação autor-texto-leitor. Por isso, é de fundamental importância que o leitor considere na e para produção de sentidos 'sinalizações' do texto, além dos conhecimentos que possui” (KOCH e ELIAS, 2008, p. 21).

O indivíduo que se propõe a ler aumenta sua capacidade de argumentação, produção escrita e senso crítico, resultando em uma melhor comunicação; para isto, deve-se reforçar o prazer pela literatura. A convivência com os livros é indispensável para ultrapassar a escolarização metódica e fazer com que o ensino desta disciplina seja disseminado de forma ampla. 
Sendo assim, o aluno que lê muito provavelmente escreverá melhor que aqueles os quais não possuem tal hábito, assim como consegue entender com mais facilidade outros conteúdos, posicionando-se de forma mais significativa. No mais, pode-se afirmar que esta maior intimidade com os textos literários poderá vir a causar a formação deste ser social em um cidadão crítico e reflexivo.

Isto posto, há a discussão sobre o desempenho ruim quanto ao ensino de Literatura e a má formação do leitor brasileiro, principalmente quando se fala nas escolas de setor público. Frequentemente, são apontados os péssimos resultados quanto a políticas educacionais neste aspecto, assim como a deficiência do acervo literário dessas bibliotecas escolares e a falta de apreço por títulos que não constituem o cânone literário provenientes de professores mais tradicionais.

No entanto, esta falha não concerne somente aos clássicos da literatura universal, mas nota-se também este distanciamento quanto à escrita local. Na verdade, pouco se vê sobre a literatura de expressão amazônica, o que faz imprimir mais a cultura do sul e sudeste no aluno ao invés de fazê-lo ler textos provenientes de autores amazônicos ou que falem da sua região também. Isso resulta em um afastamento da cultura regional e reforça a predileção por outros lugares, mesmo sendo do mesmo país.

Ademais, ao confrontar esta preferência pelo cânone literário, buscou-se falar sobre uma parte marginalizada, o papel da mulher na literatura. Deste modo, além de se utilizar um texto de cunho regional, procurou-se trazer a tona uma mulher que escreveu sobre mulheres, ocasionando numa dupla crítica ao que se convencionou como alta cultura. É imprescindível que os nortistas tenham o seu lugar na história literária do país, indo mais a fundo, a mulher da região Norte.

Para isto, é imprescindível ressaltar a influência que a crítica literária feminista exerce atualmente, visto que ao se falar nos modos de pensar a literatura na contemporaneidade, não se pode deixar de lado o alcance do feminismo e dos estudos de gênero. Vertente que desde a década de 1970 abala o cânone dos moldes tradicionais de análise literária, levando em conta o caráter mais amplo dos estudos culturais, sendo assim “A crítica literária feminista se faz interdisciplinar por definição, uma vez que ela não admite a leitura do texto em um modo desvinculado de sua exterioridade e de sua historicidade" (ALÓS \& ANDRETA, 2017, p. 20). 
Um aspecto que passa a ser discutido é de que o gênero de quem está lendo pode influenciar a forma que a obra será recebida, posto que homens e mulheres possuem pontos de vista e vivências muito distintas para a recepção do texto literário. No campo da Literatura, houve o estabelecimento da dicotomia entre o masculino que cria, sujeito da representação e o feminino que é criado, objeto representado. Em consequência, notou-se que a escrita literária não havia sido feita para mulheres, estas eram representadas, largamente idealizadas, podiam até ser personagens marcantes, mas sempre criadas e nunca criadoras.

Esta categoria de análise passa a implementar o conceito de gênero que é definido como "toda e qualquer construção social, simbólica, culturalmente relativa, da masculinidade e da feminilidade. Ele define-se em oposição ao sexo, que se refere à identidade biológica dos indivíduos" (SCOTT, 1990, p. 5). Portanto, percebe-se que gênero difere de sexo por ser uma condição imposta sobre um corpo sexuado, fazendo do ser biológico um sujeito social, sendo homem, mulher, de qualquer cor e de qualquer tipo de sexualidade.

O surgimento desta categoria marca novas possibilidades de análise teórica para as feministas contemporâneas, fomentando novos debates sobre aspectos comportamentais e relativizando os conceitos há muito conhecidos de dominação e submissão entre os sexos. A construção do conhecimento acadêmico passa a ser inovada neste quesito por causa de novas abordagens metodológicas como o pós-estruturalismo, a linguística e a psicanálise que permeiam os estudos culturais.

Assim, utilizar o gênero como categoria de análise faz com surja um significado político, visto que quando se vê dentro da perspectiva feminista, a interpretação passa a ter influências políticas ligadas a ideologias deste cunho e a percepção das relações de poder na sociedade. Deste modo, observa-se que

a crítica literária feminista pode ser vista como uma modalidade de prática política, na medida em que vincula reflexão teórica e ativismo, com vistas a alcançar a transformação da própria subjetividade. Essa transformação é o primeiro passo em direção a uma mudança social mais ampla, tanto no campo cultural quanto no campo político (ALÓS \& ANDRETA, 2017, p. 28).

Tendo sido relatado um panorama deste modo de análise, vale elencar autoras importantes para que estes alunos saibam que existem mulheres na literatura brasileira que possam ler. Dito isto, como primeiro passo da sequência básica de letramento literário, a motivação se faz necessária para induzir o aluno a querer conhecer este texto literário. 
Portanto, tratar-se-ia de falar sobre o direito que este alunado tem de se apropriar da cultura, a importância da arte escrita para o seu desenvolvimento humanístico e a relevância que por muito tempo tem sido suprimida - da mulher; falar-lhes um pouco sobre autores paraenses e mencionar a pouca visibilidade desta produção, ainda mais voltando a reflexão para a figura da mulher escritora.

É pertinente criar o debate sobre a literatura universal, a brasileira e por fim, a amazônica. Levá-los a pensar nos porquês de estudarem as obras e quais são escolhidas, que existem mais mulheres que escrevem além de Clarice Lispector e Cecília Meirelles. No mais, quando se pensa sobre isso percebe-se que "[...] ser escrita de mulher e do norte do Brasil ainda carece, para ser incluída nas agendas de leituras, de uma legitimação vinculada aos padrões estéticos e temáticos dos cânones universitário e escolar" (SANTOS \& RIBEIRO, 2013, p. 88).

E justamente por isso que uma jornalista e militante paraense foi escolhida, Eneida de Moraes que destacou-se no cenário literário através de suas proezas como cronista. Suas memórias fazem o leitor identificar o lugar, sua infância na cidade das mangueiras e muitos outros aspectos de sua vida pessoal, esta que se mistura com a sua produção escrita.

Todavia, a crônica escolhida foi Companheiras que remete a um tipo de memória específica, a do cárcere, da militância que exerceu durante o Estado Novo, quando fez parte do partido comunista. À vista disso, a década de 1930 ainda foi um momento no qual a voz feminina era muito abafada, momento em que Eneida aproveitou-se para expressar-se através desse gênero literário, com uma escrita muito transparente, falando de suas prisões e ocasionando em discussões sobre o momento político pelo qual o país passava.

Ainda como formas de motivar os adolescentes a ler tal texto, o intermediador da leitura poderia falar dos aspectos históricos nos quais a obra foi produzida para incentivá-los na interpretação e sensibilização quanto ao que estariam prestes a entrar em contato. Sendo assim, falar-se-ia da figura feminina, da literatura paraense, do contexto histórico para finalmente, introduzir o texto conversando sobre a vida da autora, as questões políticas que nortearam tal produção e finalmente realizar a primeira leitura coletiva e comentada com estes novos leitores.

Finalmente, realizada a atividade de leitura tanto coletiva quanto individual, o professor instigaria o debate acerca dos temas tratados no texto. Em consequência de serem diversos, o intermediador da experiência literária poderia solicitar a alguns voluntários que comentassem 
o texto de forma geral e depois das considerações dos alunos, pontuar temas como a tortura, a empatia, a humanidade, a mudança política e por fim, a sororidade. Tema este que carece que explanação, pois trata-se de um termo proveniente do latim cujo significado é "irmãs" e substancializa o sentimento de união entre mulheres, empatia e companheirismo quando estas buscam algo em comum, que neste caso seria sobreviver àquela cela.

\section{CONSIDERAÇÕES FINAIS}

O trabalho aqui apresentado foi pensado visando buscar a importância da arte literária na vida do aluno, discutindo a respeito do feminismo dentro da literatura e expondo-o a obras escritas por mulheres, as quais mostram a representatividade da mulher dentro da literatura, seja como autora ou personagem, quebrando o paradigma da construção literária escrita em maioria por homens. Perquiriu-se apresentar uma maneira de ensinar essa disciplina através de sequências básicas de Letramento Literário direcionadas ao Ensino Básico.

As práticas de letramento resgatam as bagagens culturais dos educandos considerando as heterogeneidades dos gêneros discursivos que vivenciam no contexto social redimensionando o processo de ensino da escrita de modo a superar as práticas opressoras que distanciam o que se ensina na escola com o que o aprendiz vivencia fora dela. Para o desenvolvimento de habilidades de uso da leitura e da escrita nas práticas sociais, tendo em vista que a linguagem é um fenômeno social concreto, permite a compreensão de que o processo de ensino-aprendizagem da escrita não pode se configurar como um mundo à parte e não ter finalidade a preparação do sujeito para a realidade na qual se insere.

Logo, compreendeu-se que, com uma maior variedade e maior diversidade dentro do ensino, o empoderamento feminino pode ser mostrado dentro da Educação Básica por meio da interpretação: a geradora do senso crítico. Conseguiu-se por meio deste trabalho enxergar como se pode ensinar literatura para alunos do ensino básico de forma a mostrar o empoderamento feminino sem deixar de lado os conceitos básicos do ensino da arte escrita, expondo uma obra feita totalmente por uma mulher sobre mulheres.

Para a adoção de estratégias de ensino que contemplem as práticas de letramento fazse necessário repensar e redimensionar as atividades pedagógicas desenvolvidas pelo professor em sala de aula. Para que o aluno se torne um sujeito autônomo e transformador da sua própria 
realidade, trabalhando com a figura feminina sem uso de estereótipos e respeitando o papel feminino na sociedade.

Espera-se que, a partir da leitura deste trabalho, os professores conscientizem-se da importância do papel feminino na Literatura, como um dos direitos de aprendizagem que a escola deve proporcionar aos estudantes e sintam-se incentivados a promover a leitura e debates sobre questões importantes como: empoderamento, artes e respeito às mulheres.

\section{REFERÊNCIAS}

ALÓS, Anselmo; ANDRETA, Bárbara. Crítica literária feminista: Revisitando as origens. Fragmentum. Santa Maria: Editora Programa de Pós-Graduação em Letras, n. 49, Jan./Jun. 2017.

CANDIDO, Antônio. Direitos humanos e literatura. In: Direitos humanos. São Paulo: Brasiliense, 1989.

CANDIDO, Antônio. O direito à literatura. Disponível em:

$<$ https://culturaemarxismo.files.wordpress.com/2011/10/candido-antonio-o-direito- c3a0-literatura-invc3a1rios-escritos.pdf >. Acessado em 10 de novembro de 2018.

CEIA, Carlos. Estudos Culturais. 2009. Disponível em: $<$ http://edtl.fcsh.unl.pt /encyclopedia/estudos-culturais/> Acessado em 27 de dezembro de 2018.

COSSON, Rildo. Letramento literário: teoria e prática. São Paulo: Contexto, 2014.

CRESWELL, J. W. W. Projeto de pesquisa: métodos qualitativo, quantitativo e misto. 2. ed. Porto Alegre: Bookman, 2010.

DUARTE, Constância Lima. Feminismo e Literatura: Discurso e História. Revista Estudos Avançados da USP. São Paulo, USP, volume 17, numero 49, setembro/dezembro 2003. p. 151-172.

GIL, Antônio Carlos. Métodos e técnicas de pesquisa social. 5. ed. São Paulo: Atlas, 2002.

HOLLANDA, Heloisa Buarque. Ensaístas brasileiras: mulheres que escreveram sobre literatura e artes de 1860 a 1991. Rio de Janeiro: Rocco, 1993.

KOCH, Ingedore Villaça e ELIAS, Vanda Maria. Ler e compreender: os sentidos do texto. São Paulo: Contexto, 2008.

LAKATOS, Eva; MARCONI, Marina de Andrade. Fundamentos da Metodologia Cientifica. 6 ed. São Paulo. Atlas, 2005. 
LOPES, M.; LIMA, K. A importância da literatura na escola: Uma proposta na formação do cidadão. ANTHESIS: Revista de Letras e Educação da Amazônia Sul-Ocidental, ano 04, no 06. Cruzeiro do Sul (AC): UFAC/CEL (Campus Floresta), 2015.

MORAES, Eneida. Aruanda. Secult: Belém, 1989.

NARVAZ, M. G.; KOLLER, S. H. Metodologias feministas e estudos de gênero: articulando pesquisa, clínica e política. 2006. Psicol. estud. [online]. 2006, vol.11, n.3, pp.647-654. ISSN 1413-7372.

SANTOS, Eunice; RIBEIRO, Lilian. A escritura literária das mulheres paraenses: recepção entre leitores/as e cânone. Itabaiana: Gepiadde, Ano 07, Volume 14: 85 - 91, jul./ dez.. 2013

PERROT, Michelle. Minha história das mulheres. São Paulo: Contexto, 2007.

PINTO, Céli Regina Jardim. Feminismo, história e poder. 2010. Rev. Sociol. Polít., Curitiba, v. 18, n. 36, p. 15-23, jun. 2010.

SCOTT, Joan. Gênero: uma categoria útil de análise histórica. Educação e Realidade: Porto Alegre, p.5-22, 1990.

VIEIRA, Hilluska. Letramento Literário - Um Caminho Possível. Revista Arredia, Dourados, MS, Editora UFGD, v.4, n.7: 117-126, jul./dez. 2015

ZILBERMAN, R. O papel da literatura na escola. Via Atlântica, n. 14, p. 11-22, 22 dez. 2008.

ZOLIN, Lucia Osana. A literatura de autoria feminina brasileira no contexto da pós-modernidade.

Ipotesi, Juiz de Fora, v. 13, n. 2, p. 105 - 116, jul./dez. 2009. 